\title{
GIS-BASED MODELLING OF MEDITERRANEAN FRUIT FLY POPULATIONS IN GUATEMALA AS A SUPPORT FOR DECISION-MAKING ON PEST MANAGEMENT: EFFECTS OF ENSO, CLIMATE CHANGE, AND ECOLOGICAL FACTORS
}

\author{
E. LIRA $^{1}$ AND D. MIDGARDEN ${ }^{2}$ \\ ${ }^{1}$ USDA-APHIS-IS, Mediterranean Fruit Fly Programme, Guatemala City, \\ Guatemala; estuardo.lira@aphis.usda.gov \\ ${ }^{2}$ USDA-APHIS-IS, Santo Domingo, Dominican Republic; \\ david.d.midgarden@aphis.usda.gov
}

\begin{abstract}
SUMMARY
The regional Mediterranean Fruit Fly Programme (Moscamed) in Belize, Guatemala and southern Mexico has applied geographic information systems (GIS) in the analysis of Mediterranean fruit fly populations since 2004. GIS allow integration of trapping data, control activities and environmental information; when combined with expert knowledge/interpretation (entomologist, ecologist and technical managers), they allow spatio-temporal analysis to determine geographic and temporal patterns, and their relationships with ecological factors and control activities. Ecological factors impacting the distribution of Mediterranean fruit fly (or medfly) populations also allow projecting pest demographics under climate change. Most of the prediction models of climate change indicate that the temperature will increase in the coming years. Temperature is a key ecological factor for insects in general, and medfly is no exception. Auclair et al. (2008) used the climate-host-insect interaction to develop predictive tools related with El Niño Southern Oscillation (ENSO) conditions, under the hypothesis that increasing temperatures will also increase medfly populations. A combination of GIS, statistical analysis, and climate change predictions indicate that hot El Niño years increase the reproductive rate of the pest, whereas cold La Niña years will have the opposite effect. With the medfly prediction model, early warnings can be provided to high-level decision makers and programme managers to act in an effective and timely-manner, including shifting in programme strategies and assigning larger budgetary resources to the programme when expecting difficult years.
\end{abstract}

Key Words: Geographic information systems, spatial-temporal analyses, temperature, El Niño Southern Oscillation (ENSO), La Niña years, Tephritidae, Ceratitis capitata, Belize, Guatemala, Mexico, population behaviour, population distribution, prediction models Development and Field Application, pp. 483-504. CRC Press, Boca Raton, Florida, USA. (C) 2021 U. S. Government 


\section{INTRODUCTION}

The Mediterranean Fruit Fly Programme (Moscamed), managed jointly by the governments of Guatemala, Mexico and the USA, has been operating since 1977 to contain the Mediterranean fruit fly (Ceratitis capitata Wied.) (or medfly) in Guatemala and to protect the areas free of this pest in Guatemala, Mexico, Belize and the USA (Gutiérrez Samperio 1976; Enkerlin et al. 2015, 2017). Moscamed conducts two main activities:

1. Surveillance, through pest monitoring in infested areas, as well as detection and delimitation of the pest in areas of low pest prevalence and pest free areas using a geo-referenced trapping system located in Guatemala, Mexico and Belize; and

2. Control, through area-wide integrated pest management (AW-IPM) for population suppression and eradication, using a combination of environment-friendly techniques including the Sterile Insect Technique (SIT), aerial and ground sprays of an organically-approved insecticidal bait (spinosad), bait stations, and quarantine checkpoints to monitor and reduce movement of infested fruit into medfly free areas.

In 2004, Moscamed implemented a geographic information system (GIS) to manage the information related with detection of the pest, sterile fly releases, and the other activities involved in the AW-IPM activities. Since that time, information about ecological factors, such as hosts, temperature and rainfall, has been incorporated into the GIS. The GIS dataset has enabled new perspectives of the ecology and behaviour of the medfly populations but understanding the population ecology of medfly in Guatemala remains a key programme challenge. The relationship between coffee, Coffea arabica L. (as the main host) and fly captures was explained by Midgarden and Lira (2008). In addition, Auclair et al. (2008) found relationships between El Niño and medfly outbreak years by combining trapping and weather information.

One of the main factors that regulate the medfly populations is temperature. As with most insects, the medfly generational time is determined by degree-day accumulation. About $328 \hat{\mathrm{C}}$ degree-days are needed to complete one life cycle from egg to adult (Grout and Stoltz 2007). The amount of time needed for this accumulation varies with temperature, and therefore also with altitude. Degree-days are the accumulation of heat units above a "base temperature" (the minimum needed for development) and below a thermal maximum (above which development is also halted) over a 24-hour period (Pedigo 1996). Below a minimum temperature threshold, no development takes place, but above it, heat units drive development. In the case of the medfly, USDA (2003) indicated that its lower threshold is $\sim 12 \hat{\mathrm{u} C}$ and its upper threshold is $\sim 28^{\circ} \mathrm{C}$.

Temperature is not only important for medfly, but the increase of temperature is also one of the indicators of climate change (IPCC 2018). Climate can be defined as the long-term statistics of the meteorological elements in one particular area (WMO 1992), thus climate change is a difference in the long-term statistics of a given area between two different periods. Rahmstorf et al. (2012) observed that global mean temperature has been increasing due the climate change at $0.16{ }^{\circ} \mathrm{C}$ per decade. In areas below the upper threshold above which the medfly development is limited, these increases will have an impact on medfly population growth by shortening the time required for its life cycle, allowing the fly to complete more generations in the same time period, resulting in a higher rate of population increase. 
Auclair et al. (2008) used an analysis of the climate-host-insect interaction to develop predictive tools related with El Niño conditions, under the hypothesis that an increase in temperatures will also cause increases in medfly population growth. These models have been used in Moscamed as an early warning system of pest population's growth. More recently we integrated other ecological factors, including soil types, to generate maps of the potential distribution of medfly, and how this distribution will be affected if temperatures continue to increase.

This chapter describes how Moscamed uses GIS to integrate the medfly ecology with observed patterns of populations, and how this information can be incorporated into prediction models that consider climate-host-medfly interaction in support of the pest management decision-making process.

\section{MEDITERRANEAN FRUIT FLY PROGRAMME}

Medfly was reported first time in Guatemala in 1975. In 1977, the governments of Guatemala, Mexico and the USA established Moscamed, a joint programme with the objective of protecting and promoting the fruit production in all three countries by containing the medfly in Guatemala (Enkerlin et al. 2015, 2017). Currently Moscamed operates in the state of Chiapas in Mexico, Guatemala and Belize to protect the medfly free areas in these countries and in the USA. The geographic area where Moscamed operates is shown in Fig. 1.

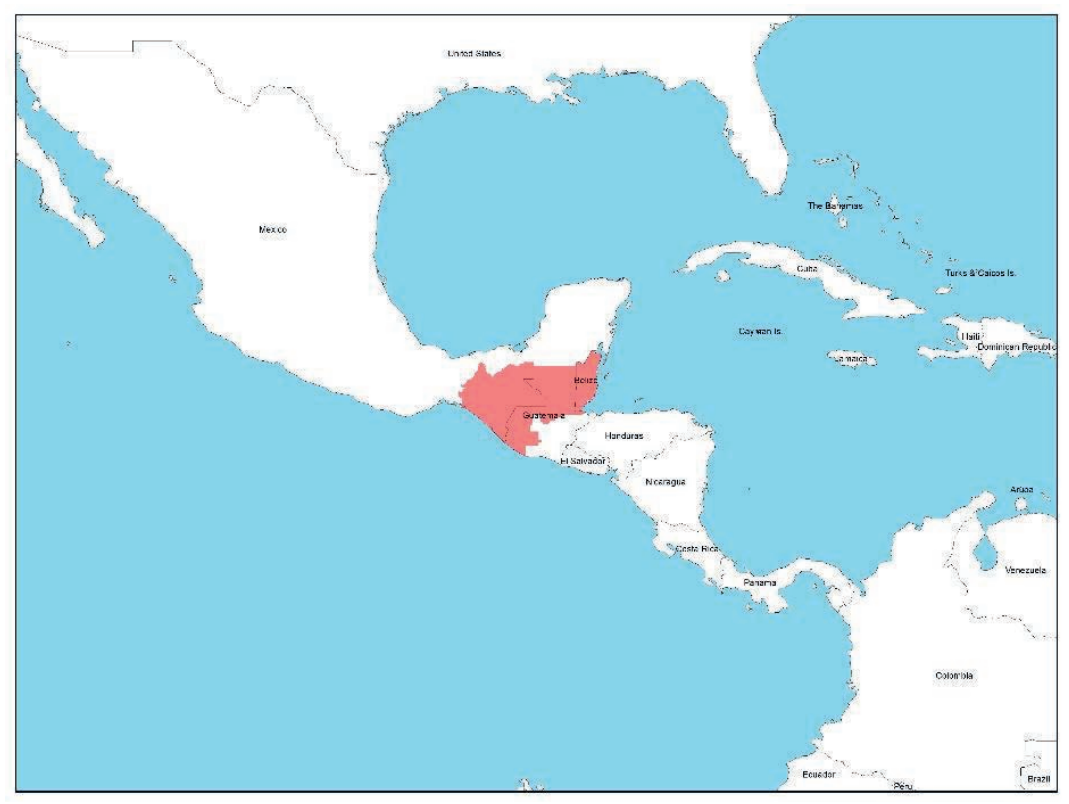

Figure 1. Area where the regional Moscamed programme operates in Belize, Guatemala and the state of Chiapas in Mexico to contain the invasive medfly, which is already established in Central and South America (credit Moscamed). 
In order to detect the pest, Moscamed currently maintains a trapping network of 23256 traps and conducts fruit sampling in strategic places. Coffee is the main and most abundant medfly host in this area. Moscamed, based on the reports of the coffee national institutions in Guatemala and Mexico, estimates that coffee covers an area of $5194 \mathrm{~km}^{2}$. Therefore, a majority of the traps are installed in coffee production areas. The trap locations and the coffee areas are presented in Fig. 2. In 2017, Moscamed covered an area of $171102 \mathrm{~km}^{2}$, as can be seen in Fig. 3. Of that area, $87 \%\left(149110 \mathrm{~km}^{2}\right)$ is considered as Pest Free Area, and most of the efforts and resources are oriented to maintain the pest free area status. A further $6 \%\left(9454 \mathrm{~km}^{2}\right)$ is considered as Low Prevalence Area and 7\% (12 $\left.538 \mathrm{~km}^{2}\right)$ as Suppression Area.

The main control activity of the programme is the SIT, which is applied on an area-wide basis for prevention, eradication, and containment, depending on the presence of the pest (Hendrichs et al. 2021). The sterile fly densities (males/hectare) are determined for areas called "release blocks" based on the Rendón Method (Rendón 2008), with the aim of releasing higher densities in areas with higher pest population levels. Blocks are visited once or twice per week and evaluated on a weekly based to make adjustments in density, shape or location when needed. Weekly, Moscamed produces 1.4 billion sterile pupae and releases them in an area of around $5000 \mathrm{~km}^{2}$ in Mexico and Guatemala. The SIT is combined with other control methods such as ground bait sprays, bait stations, and aerial bait sprays where populations are too high for only SIT releases. The distribution of sterile male release blocks and densities during one particular week in 2017 is presented in Fig. 4.

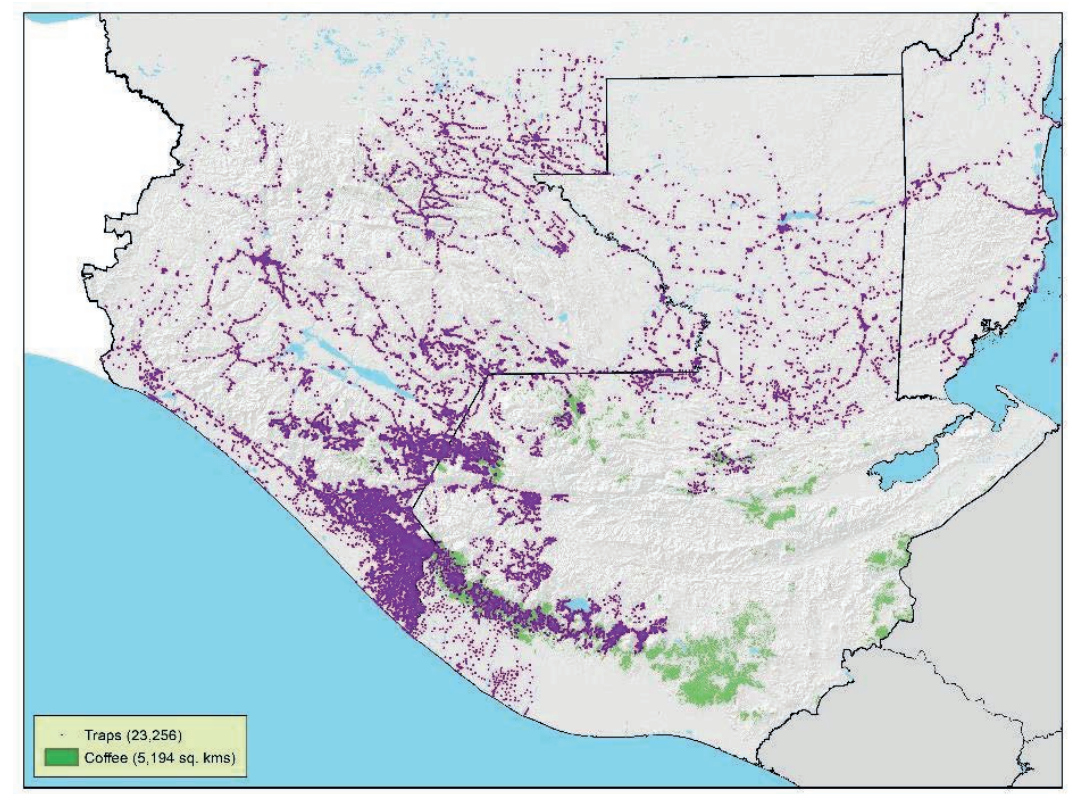

Figure 2. Moscamed trapping network in 2017, overlapping the main medfly host in Belize, Guatemala and the state of Chiapas in Mexico (credit Moscamed). 


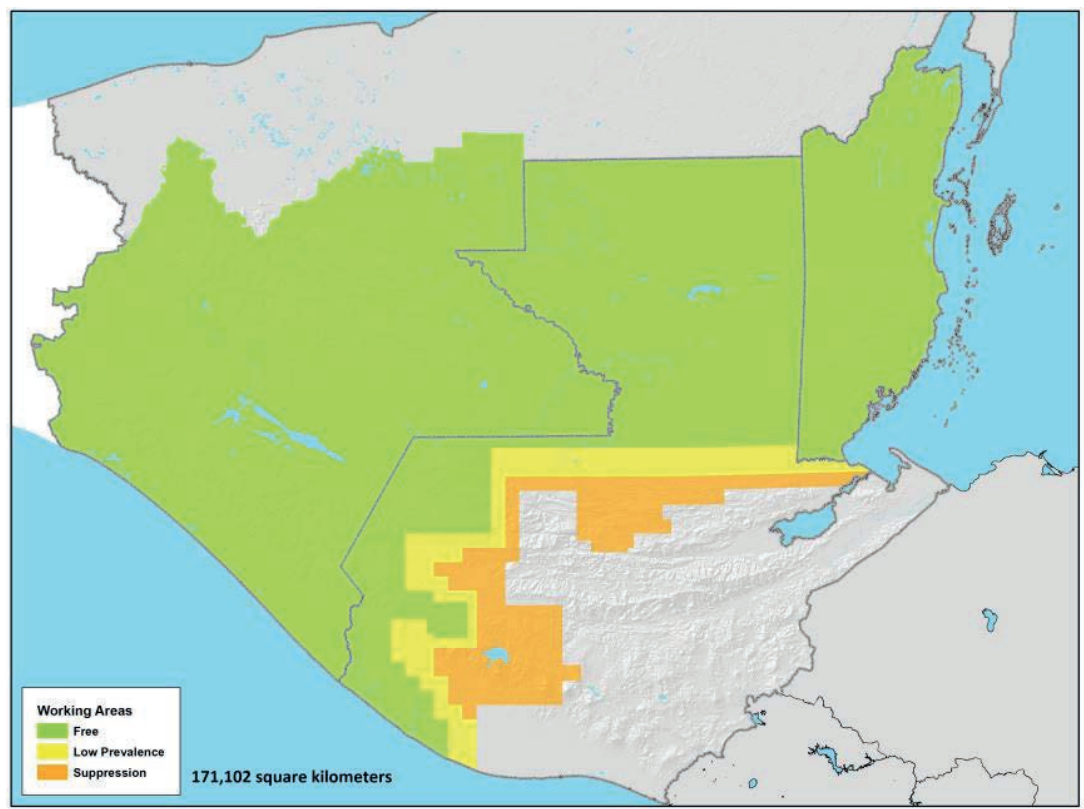

Figure 3. Moscamed working areas in 2017 in Belize, Guatemala and the state of Chiapas in Mexico (credit Moscamed).

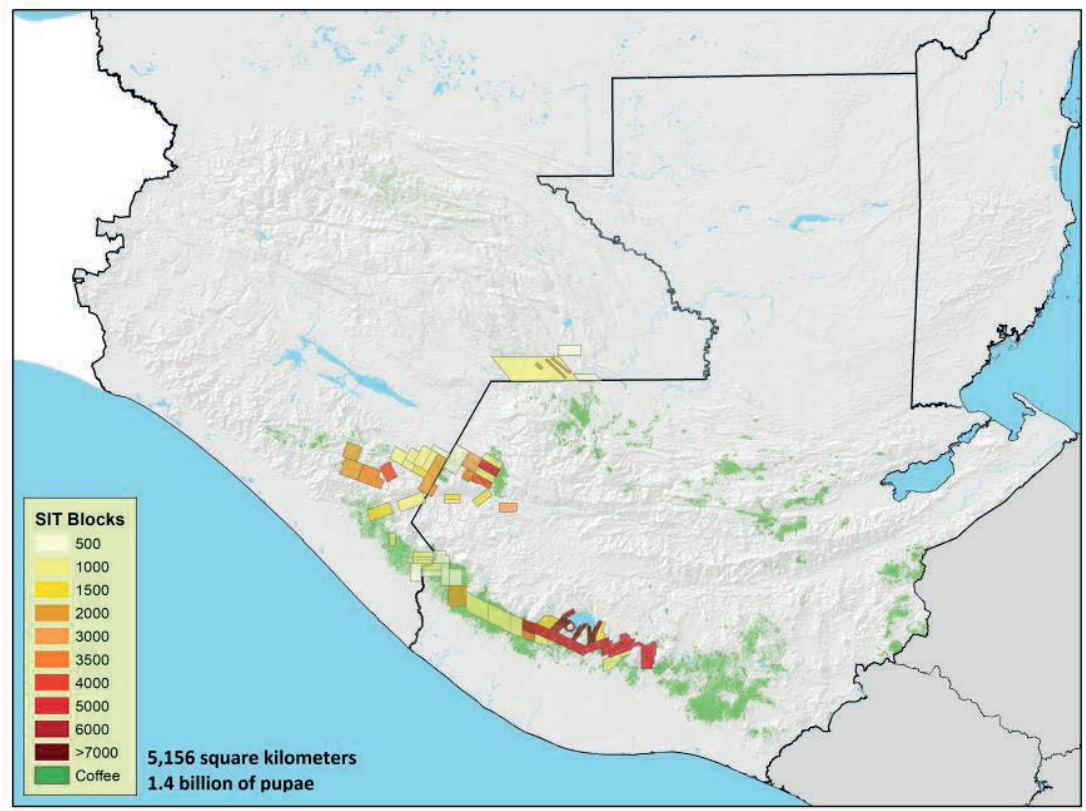

Figure 4. Sterile medfly release blocks in Guatemala and the state of Chiapas in Mexico. Numbers indicate fly release densities per hectare and per week (credit Moscamed). 


\section{CLIMATE CHANGE AND ITS IMPACT ON MEDFLY}

The World Meteorological Organization (WMO) defines climate as the "synthesis of weather conditions in a given area, characterized by long-term statistics (mean values, variances, and probabilities of extreme values) of the meteorological elements in that area" (WMO 1992). The Intergovernmental Panel on Climate Change (IPCC) refers to climate change as a change in those long-term statistics of weather conditions for an extended period, typically decades or longer (IPCC 2018). Even though climate change may be due to natural processes, the main concern for IPCC is that since 1950's the climate change has been accelerating and evidence is accumulating that it is caused by anthropogenic factors, with the increase of temperature being one of the indicators of climate change. Houghton (2015) indicates that the climate change can be observed as an increase in the mean, in the variance or in both. Considering temperature as the variable of interest, if the "new" climate has an increased mean temperature, this suggests less cold weather, more hot weather, and/or that the extreme hot weather will be higher. If there is an increase in the variance, it can be expected that there will be colder weather and hotter weather in the new climate. If there is an increase in both, the mean and the variance, then it is expected that there will be more hot weather, and the probability of occurrence of extreme hot weather will also be higher.

The IPCC considers that the three main lines of evidence of the climate change are: a) land and ocean surface temperature anomaly, b) sea level change, and c) greenhouse gas concentrations in the atmosphere (IPCC 2018). These three lines have shown an increase, which has become more evident after 1950. According to the IPCC, the changes in these three variables are related to the increase of emissions of the anthropogenic gases, which have accelerated global warming and in consequence catalysed changes in the climate. The IPCC forecast is that the temperature will continue increasing in the next decades (IPCC 2007). The IPCC observations regarding temperature indicate that the total temperature increase from 1850-1899 to $2001-2005$ is $0.76^{\circ} \mathrm{C}\left[0.57^{\circ} \mathrm{C}\right.$ to $\left.0.95^{\circ} \mathrm{C}\right]$. Hansen et al. (2013) observed that the global surface temperature in 2012 was $+0.56^{\circ} \mathrm{C}\left(1^{\circ} \mathrm{F}\right)$ above the $1951-1980$ base period average.

In this chapter, the increases of temperature are the main concern for medfly, since temperature is a key factor in its development and population dynamics. As will be discussed in Section 6, changes in temperature may trigger increases in medfly population levels.

\section{GEOGRAPHIC INFORMATION SYSTEMS (GIS)}

In a geographic information system (GIS), the physical world is represented as thematic layers, so that it can be described and analysed. A GIS is considered a computerized system used to acquire, store, analyse and display geographic information, which can be used to support the decision-making process. The main advantage of using a GIS is that spatial-temporal analyses can be conducted, and the results presented in an "easy-to-read" format such as maps, which are graphic and simplified representations of the reality. 
With Moscamed in Guatemala establishing its GIS in 2004 (Lira 2010), the trapping network information generated by its operations is converted into geographic data and stored with other geographic layers such as land use, temperature, rainfall, altitude, and soil types in a digital format. Using different GIS operations, modelling and analyses of the medfly populations are conducted and different scenarios are generated. With the adequate cartographic techniques, i.e. generalization and symbolization, maps are provided to decision-makers to support their pest management decisions. According to Huisman and de By (2009) symbolization is the process to choose the visual design employed to communicate information on a map in an efficient manner by combining the visual variables of colour, intensity, size, orientation, transparency, and fill. The same authors indicate that generalization is the process of producing a graphic representation of a smaller scale from a larger original scale.

Midgarden et al. (2014) described that, for tephritid fruit fly programmes, GIS serve as a bridge between the trap samples and the spatial analysis methods. These methods enable: 1) improvement in the way to report and summarize the collected information in a more meaningful way; 2) identification of unrecognized patterns of population growth and spread, and 3) development of improved integrated pest management strategies. In the case of Moscamed, the use of GIS and improved understanding of medfly ecology allowed to change the containment and eradication strategies of the medfly in Guatemala. Starting in December of 2007, the Gradual Advance Plan (GAP) was implemented (McGovern et al. 2008). The GAP consists of pushing back the leading edge of the infestation by 10 to $20 \mathrm{~km}$ per year, with the subsequent movement of the low suppression and suppression areas into the adjacent infested areas in a strategy known as the "rolling carpet" approach (Hendrichs et al. 2021). The GAP allowed expanding the medfly-free area $150 \mathrm{~km}$ into Guatemala in less than four years, despite severe budget reductions (Enkerlin et al. 2017).

\section{POPULATION BEHAVIOUR OF MEDITERRANEAN FRUIT FLY IN GUATEMALA}

Over the year, in south-western Guatemala, the growth of medfly populations in infested areas has a logistic trend, with an S-shaped curve. Fig. 5 describes this behaviour in four phases. The population growth begins in November of each year, reaching maximum growth rate in January, and reaching the maximum population size in February. After that the growth rate decreases, and then the fly population gradually declines, and finally reaches a minimum in October/November. Because of the detection system used (mainly based on adult traps), this behaviour is measured as captures of adult flies, and it seems to occur independent of the availability of maturing coffee berries (Fig. 6). However, as explained by Midgarden and Lira (2008), the reason for this time-displacement is that the populations seen as adults were laid as eggs before, when coffee berries were available.

Depending on the altitude and the host availability, these 4 phases can occur earlier or later in the year, especially phases 2 and 3. But the general pattern is repeated every year. It can be said that the "medfly-year" runs from November to October. 


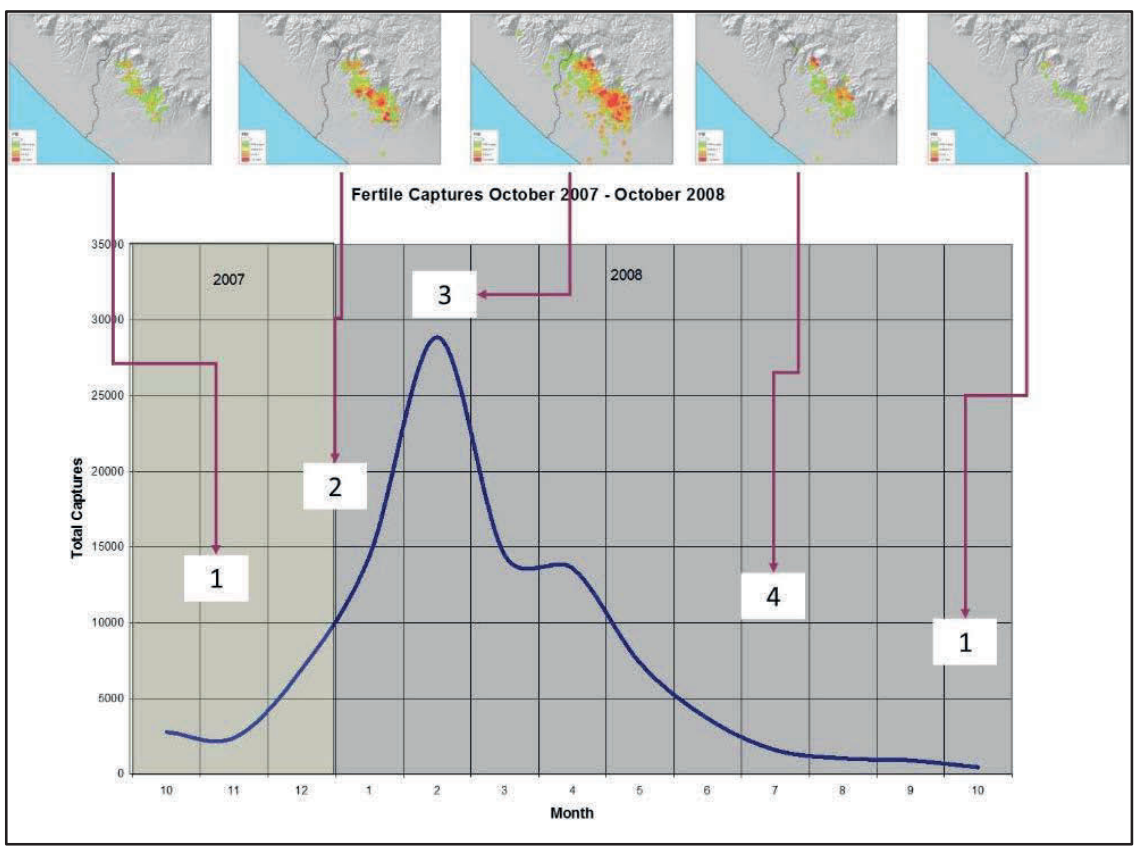

Figure 5: Four phases of medfly population behaviour in south-western Guatemala. 1. Beginning of population growth; 2. Maximum growth rate; 3. Maximum population size; 4. Decreasing rates and population declines, reaching a minimum size (credit Moscamed).

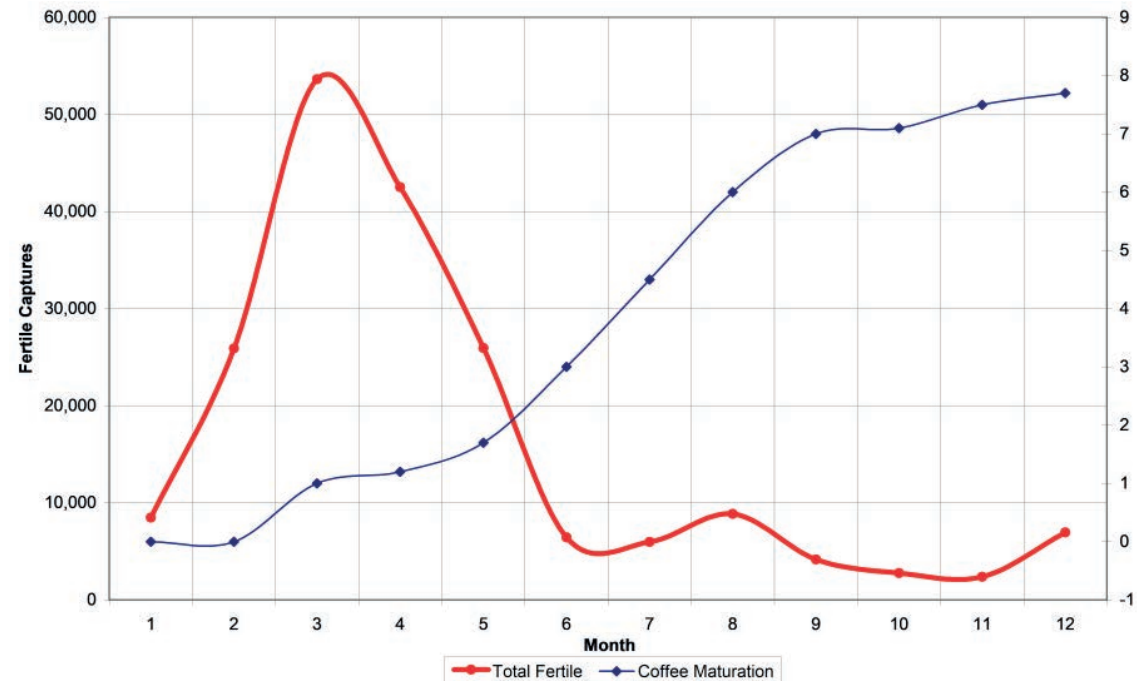

Figure 6. Relationship between captures of fertile medflies and coffee maturation throughout the year 2007 in the south-western region of Guatemala between 600 and $1500 \mathrm{~m}$ above sea level (the authors, based on Moscamed and ANACAFE 2008 data). 


\section{MEDITERRANEAN FRUIT FLY ECOLOGY: EFFECTS OF HOST, TEMPERATURE AND SOILS ON MEDFLY POPULATIONS}

The population behaviour of medfly in Guatemala, described in the previous Section, can be explained by different ecological factors. We analysed three factors affecting medfly: host, temperature, and soils. The contribution of each of these ecological factors to medfly populations is discussed in this Section.

\subsection{Main Host}

Coffee is the main host of medfly in southern Mexico and Guatemala (Gutiérrez Samperio 1976). Midgarden and Lira (2008) explained how the coffee phenology (including events such as flowering and fructification) interacts with medfly biology. According to these authors, the adult fly population outbreaks may appear in one location after the coffee harvest, while the growing larval population was actually present at another location and at an earlier time (during the coffee berry fructification period).

This "shift" of the pest in time and space is related with the altitude gradient in which the main coffee production areas in Guatemala are located, with elevations varying from $\sim 400$ to $\sim 2100$ meters above the sea level. This altitudinal gradient drives a gradient in the time of maturation and harvesting of coffee; in consequence adult flies can infest the coffee berries at lower elevations in July, and gradually move up to higher elevations following the maturing phenology of coffee final harvest in December or later.

Midgarden and Lira (2008) observed that, due to the pupation time after coffee harvest, the emergence of the highest population of adult flies will occur in MarchApril of the next year. At that moment, coffee berries are scarce, likely resulting in extensive dispersal of mature adults to search for other available hosts including mandarin (Citrus reticulata L.), orange (C. sinensis L.), peach, (Prunus persica L.) and pear (Pyrus communis L.) at middle to high altitudes and guavas (Psidium guajava L.), caimito (Chrysophilum caimito L.) and tropical almond (Terminalia catappa L.) at lower altitudes (Enkerlin et al. 2016). In summary, Midgarden and Lira (2008) concluded that

"flies are captured in detection traps in March through April and can be seen as part of an ecological "shell game": the fly population outbreaks appear in one location in April (non-infested or host-poor areas west of the leading edge of the pest population), while the growing population was actually present at another location months earlier (e.g. December in untreated coffee areas to the East)".

Fig. 6 summarizes the coffee-medfly relationship explained by Midgarden and Lira (2008) in relation to the months of the year. In the left Y axis, the number of fertile or wild fly captures per month is presented, and in the right $Y$ axis the coffee maturation level is shown, in a scale of 0 to 8 , being 0 no berries at all, and 8 total maturation. After December it is expected that most of the harvest occurs, "cleaningup" mature coffee berries from the field. 


\subsection{Temperature}

Regarding temperature, Ricalde et al. (2012) indicated that an insects' development depends on thermal requirements, with each insect species having an optimal temperature range for development, limited by lower and upper thresholds (base temperature $(\mathrm{Tb})$ and upper limit $(T S)$ ) plus a required thermal accumulation for developmental transition to complete a life cycle. The thermal accumulation between $T s$ and $T b$ in one day ( 24 hours) is measured in "degree-days". These are calculated as follows (example): if $\mathrm{Tb}$ of an insect is $10{ }^{\circ} \mathrm{C}$, and temperature remains constant at $15{ }^{\circ} \mathrm{C}$ for 24 hours, 5 degree-days will be accumulated.

Ricalde et al. (2012) found that the base temperatures for medfly were between $8.47^{\circ} \mathrm{C}$ and $9.60^{\circ} \mathrm{C}$ and the degree-days required to complete the life cycle varies from 328 to 350, depending on the location. This is in accordance with Grout and Stoltz (2007), who found that for C. capitata be able to complete an egg-to-egg cycle (hatching from the egg, larvae growth, transformation into a pupae, emergence as an adult, reaching sexual maturity, copulation and laying of viable eggs), the thermal constants are: 337.8 degree-days, minimum development threshold of $9.6^{\circ} \mathrm{C}$, maximum development threshold of $33.0^{\circ} \mathrm{C}$, and optimum development threshold of $28.5^{\circ} \mathrm{C}$. According to USDA (2003), the parameters for medfly are: a) 328 degreedays for completing a life cycle, b) $\sim 12^{\circ} \mathrm{C}$ as minimum threshold, and c) $\sim 28^{\circ} \mathrm{C}$ as maximum. These estimates vary among them, but they can be used as reference to estimate the length of medfly life cycle.

Using the Grout and Stoltz (2007) thermal constants as reference, it is possible to estimate the length of the life cycle. If it is assumed that the daily temperature is constant at $28.5^{\circ} \mathrm{C}, 17.87$ days will be required to complete a life cycle, since each day 18.90 degree-days will be accumulated $\left(28.5{ }^{\circ} \mathrm{C}\right.$ minus $\left.9.6^{\circ} \mathrm{C}\right)$ to reach the needed 337.8 degree-days. If the temperature is constant at $20^{\circ} \mathrm{C}$, the number of days to complete a life cycle will be 32.48 , since every day 10.40 degreed days will be accumulated $\left(20{ }^{\circ} \mathrm{C}\right.$ minus $\left.9.6{ }^{\circ} \mathrm{C}\right)$. This dependency of insect development on temperature drives the population's behaviour: temperature speeds up or slows down the life cycles, and in consequence the resulting number of flies in a fixed period. If it is considered that the "medfly-year" runs from November to October (as indicated in Section 5) and the parameters proposed by USDA (2003) are applied to the average daily temperature of one weather station in one site of Moscamed's suppression area, it can be estimated that the number of life cycles for the "medfly-year" starting November $1^{\text {st }}$ of 2012 to October $30^{\text {th }}$ of 2013 is 7.74 (Fig. 7).

Based on these life cycles, and considering the other ecological factors as constant (host availability and soils) and an estimated population increase rate of 6x (Rendon 2008), from one wild female fly on day one of the medfly-year, after 365 days a medfly population of 1021780 flies can be expected (Fig. 8). It is important to stress that the quantitative estimate of the number of flies from one female does not relate directly to real population patterns (Fig. 5) because it considers only potential maximum, and not limitations from factors like host availability or predation.

To measure the impact of increasing temperatures on medfly populations, and assuming an increase of $1^{\circ} \mathrm{C}$ of temperature, the same estimation was made. That estimation indicates that with such a temperature increase, the number of life cycles in 365 days will be 8.86 (Fig. 9). Even though that it is only 1.11 more life cycles, 
under the same assumptions (host availability, soils, and population increase rate), with that increase of temperature, a population of 7463038 flies (more than 7 times higher) is to be expected after 365 days (Fig. 10). These estimations reflect the drastic effect of temperature on medfly populations.

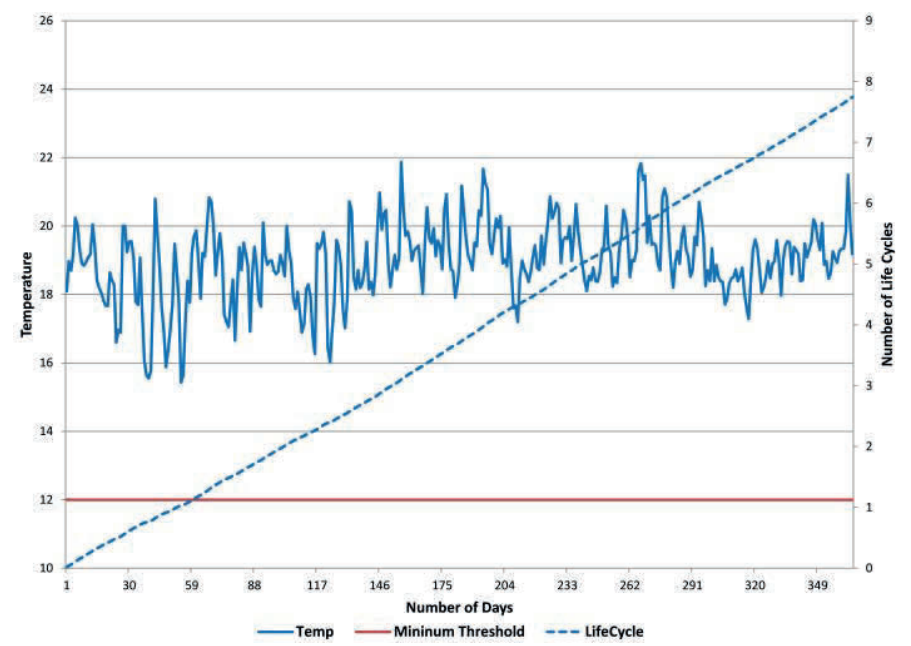

Figure 7. Average daily temperature and number of medfly life cycles expected from November $1^{\text {st }}$ of 2012 to October $30^{\text {th }}$ of 2013 in a coffee farm in the suppression area in Guatemala at 1600 meters above sea level (the authors, based on weather information of ANACAFE 2014).

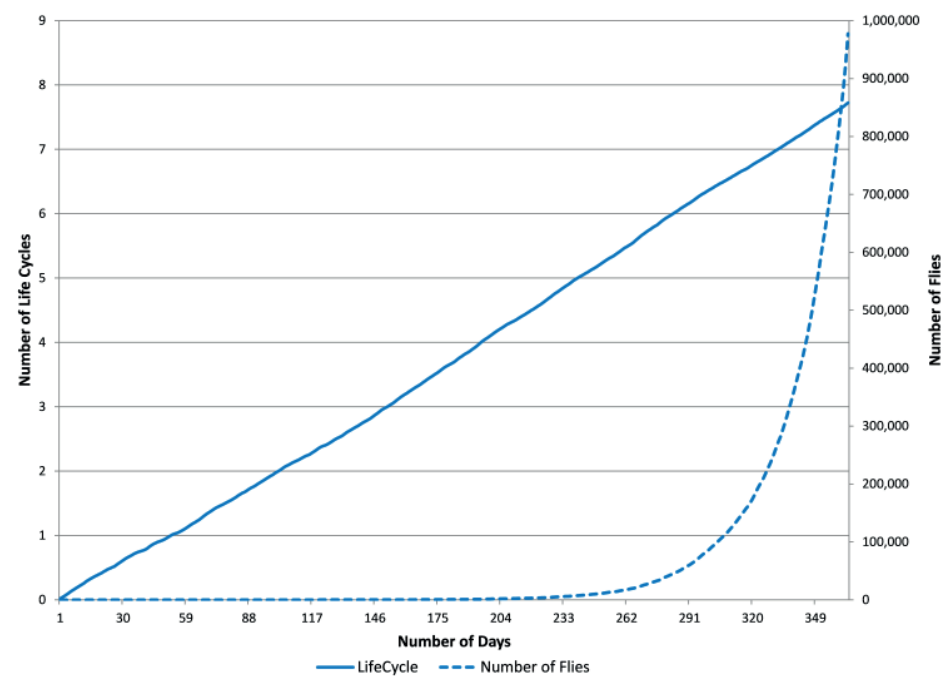

Figure 8. Number of life cycles and number of medflies (offspring from one wild female fly on day one) expected from November $1^{\text {st }}$ of 2012 to October $31^{\text {th }}$ of 2013 in a coffee farm in the suppression area in Guatemala at 1600 meters above sea level (the authors, based on weather information of ANACAFE 2014). 


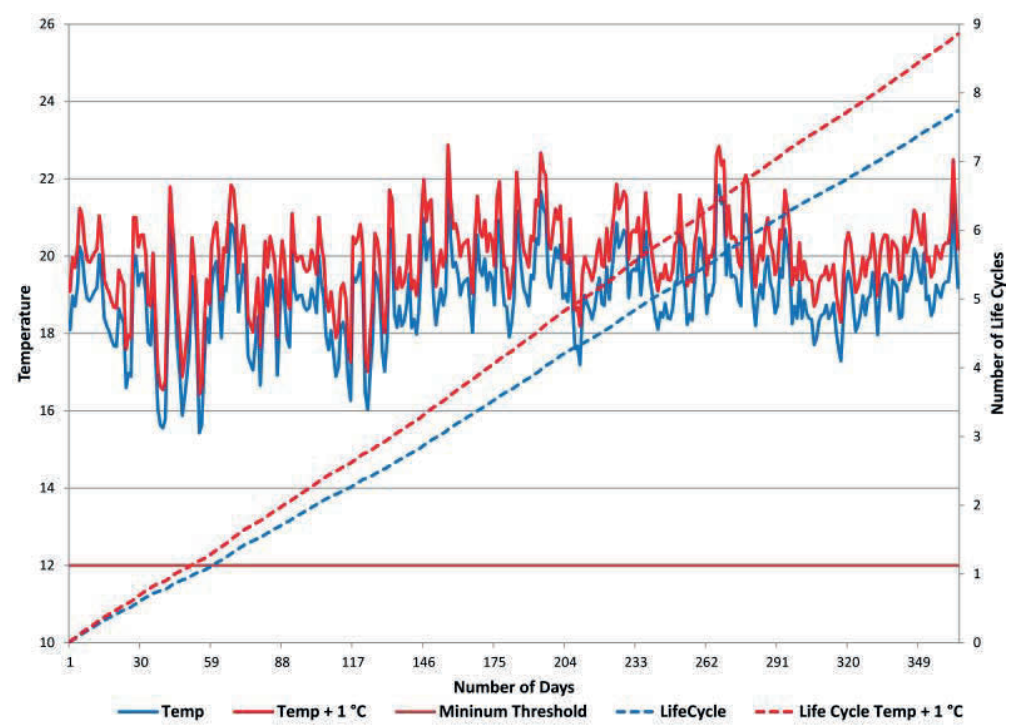

Figure 9. Number of medfly life cycles expected in a year in a coffee farm in the suppression area in Guatemala at 1600 meters above sea level in relation to an average daily temperature increase of $1^{\circ} \mathrm{C}$ (the authors, based on weather information of ANACAFE 2014).

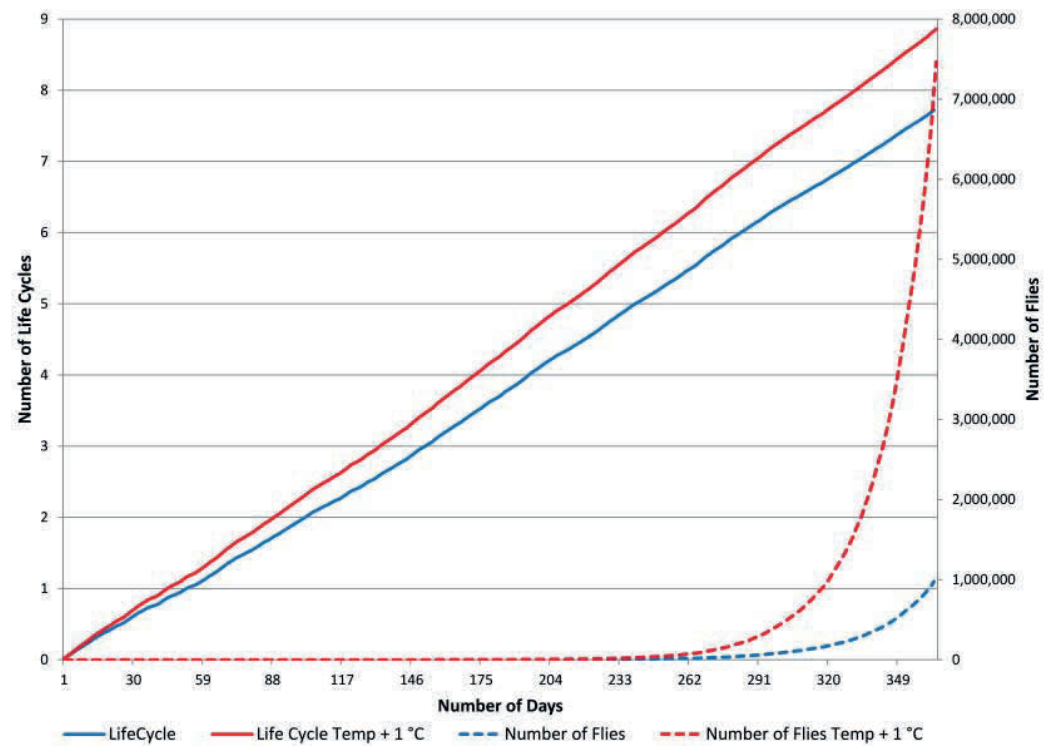

Figure 10. Number of medfly life cycles and number of medflies (offspring from one wild female fly on day one) expected in a year with an average daily temperature increase of $1^{\circ} \mathrm{C}$ (the authors, based on weather information of ANACAFE 2014). 


\subsection{Soil Texture}

The last factor of the three factors considered here is soil. Under similar conditions of host availability and temperature, differences in the size of medfly populations have been found. Those differences might be explained by factors such as soil types. Larval and, mainly, pupal stages of the medfly occur in the soil, so soil conditions will affect medfly pupae survival. Eskafi and Fernandez (1999) found that pupal survival was negatively correlated with the soil bulk density, but positively with percentage of soil porous space and percentage of water saturation.

To estimate the relationship between soil texture and the presence of medfly 17014 traps in Guatemala were used. For each trap, the maximum number of flies captured from 2004 to 2016 was obtained and the traps were overlaid with a map of soil textures (Simmons et al. 1959; MAGA 2000). The textures were classified from 1 to 10 , according to the content of sand. In this classification, 1 included very clayey soils (almost no sand and high-bulk density) and 10 included very sandy soils (almost only sand and low high-bulk density). The result of overlaying the traps with the classified soil textures was that each trap had a texture class and the maximum number of flies captured. The average of the maximum number of flies captured per texture class classified by sand content was calculated and plotted indicating a positive relationship between fly captures and the content of sand (Fig. 11).

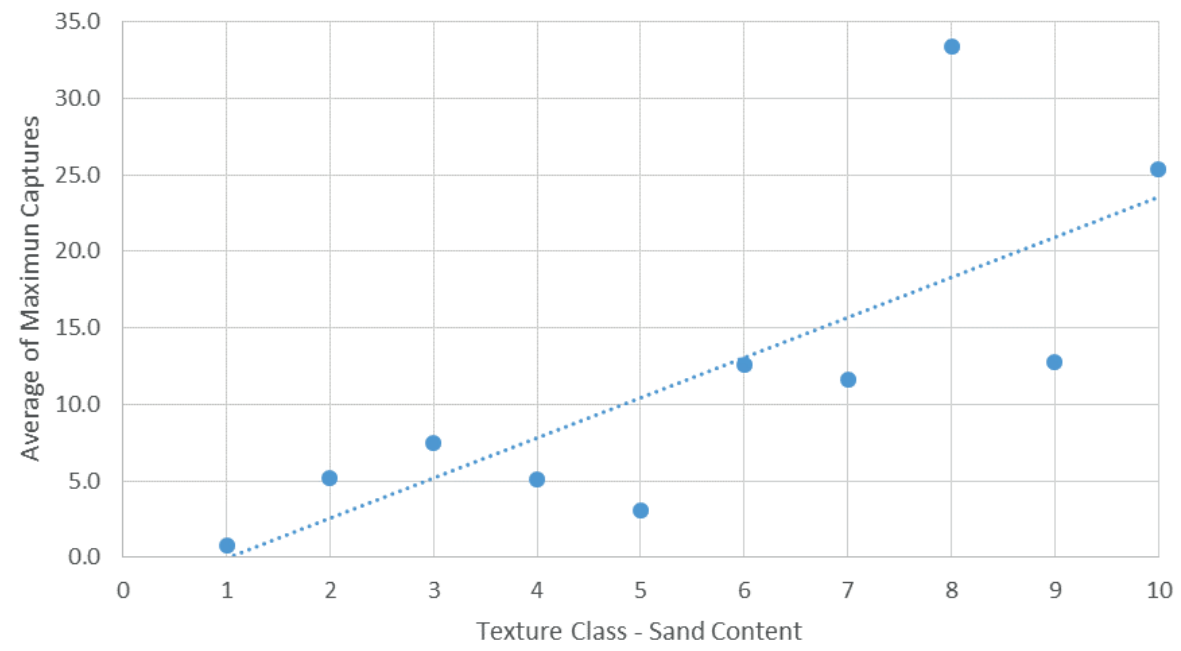

Figure 11. Relationship between medfly captures and soil texture classes (1 almost no sand and 10 very sandy soils) (the authors, based on data of Moscamed and the soil information of MAGA 2001).

From the three factors analysed, we can infer that the maximum potential for presence of medfly occurs in coffee production areas with yearly average temperatures of around $20^{\circ} \mathrm{C}$, and sandy-loam soils; being the coffee availability for oviposition the main factor, either a) promoting population growth or b) restricting and decreasing population growth. 


\section{MEDITERRANEAN FRUIT FLY CAPTURES FROM 2004 TO 2016}

Even though the described population curve is observed every year, the difference from one medfly-year to another is that the maximum population size might be higher or lower. Fig. 12 presents a sequence of the yearly average fly per trap per day (FTD) of the wild populations from 2004 to 2016.

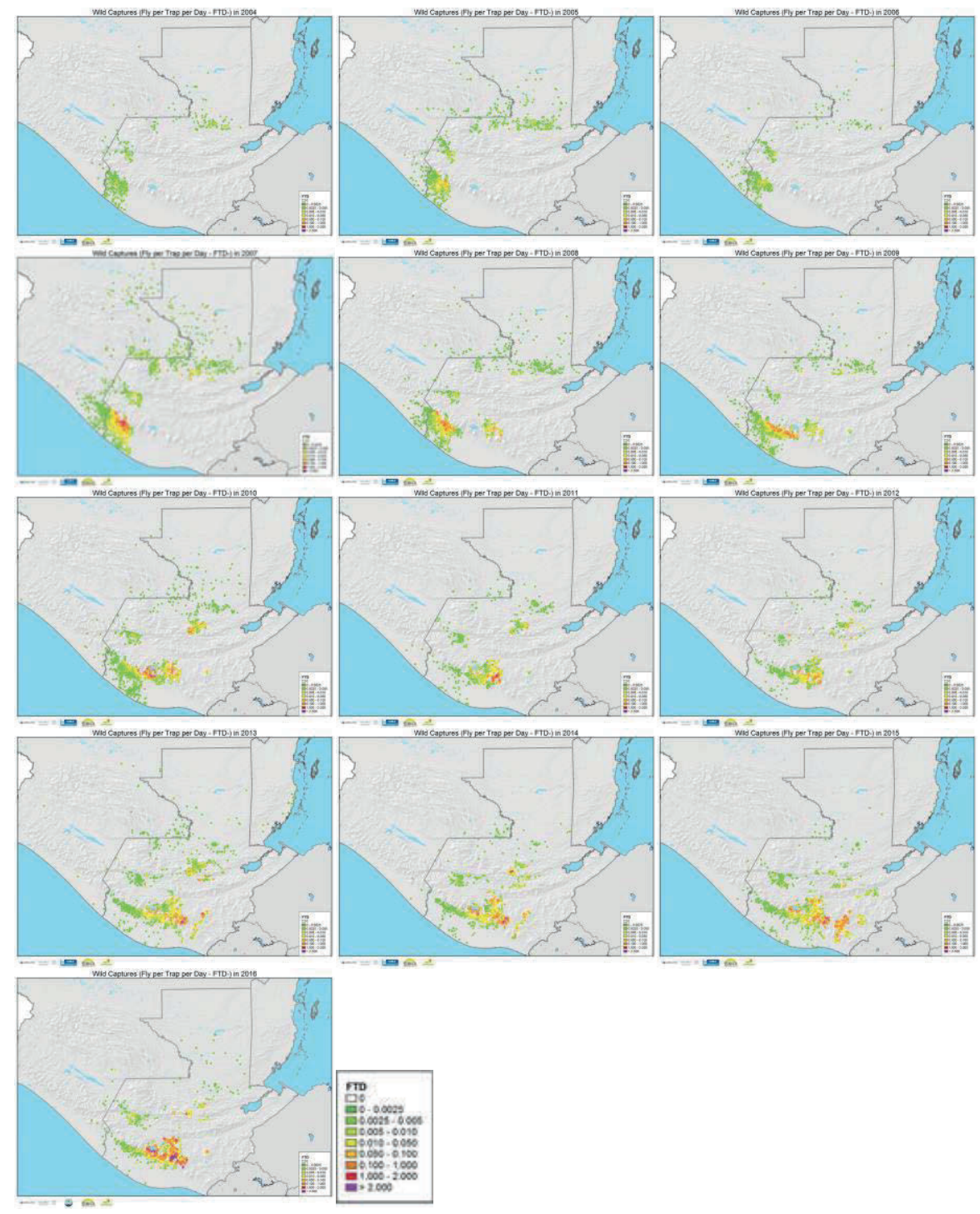

Figure 12. Average Fly per Trap per Day (FTD) numbers per year, from 2004 to 2016 in Guatemala and southern Mexico (credit Moscamed). 
During this 13-year period it has been observed that there have been "good" and "bad" years regarding the number of flies captured. A "good-medfly-year" occurs when the maximum population size is low, as measured by relatively few captures in the infested areas, and as a consequence few or no finds in the neighbouring low prevalence and free areas. In the sequence shown in Fig. 12, 2004, 2006, 2012 are considered as "good" years. In contrast, a "bad-medfly-year" occurs when the maximum population size is higher than normal, and the number of captures is very high in the infested areas, spreading into the low prevalence and free areas. In the period of 2004 to 2016, years 2007 and 2016 are considered "bad" years.

Even though most of the control activities (SIT application, ground and aerial sprays, quarantine, and mechanical control) were conducted in a similar way between 2004 and 2016, a "jump" from one good year to a bad year was observed periodically, with no apparent reason. For example, between 2006 and 2007 a huge population increase occurred (Fig. 13). There are several hypotheses that have been advanced to explain this pattern.

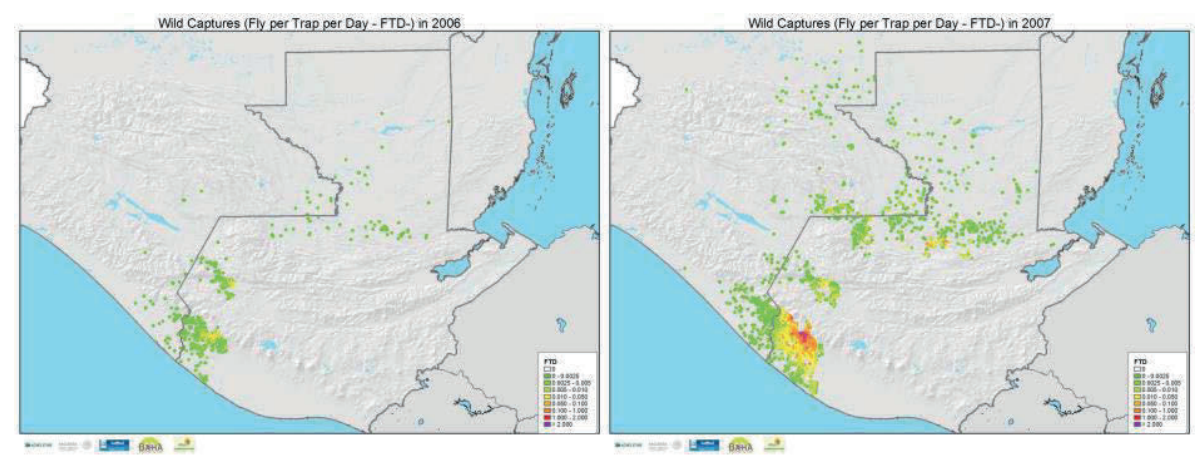

Figure 13. Comparison of wild medfly captures in the years 2006 and 2007, showing a drastic increase in the number of captures in 2007 (credit Moscamed 2017).

Auclair et al. (2008), suggested that the periodic changes are related to the "El Niño" pattern (El Niño Southern Oscillation or ENSO) (Wang et al. 2017). They analysed the trapping information and related it with temperature and rainfall, finding a correlation between the weather conditions in the "lead-in" year (6 months previous to the peak of the captures) and medfly population dynamics. The "bad" years were classified as "outbreak years" or "medfly storm years", and the "good" years as normal years. These relationships indicated that dry and hot "lead-in" years will produce a "medfly-storm" or an "outbreak year", while wet and cool "lead-in" years will produce lower than average trap captures or normal years. Auclair et al. (2008) concluded that before a medfly-storm year:

"rainfall was less and temperature was greater on average during the key months of population growth during the lead in years compared to average". 
These conditions, in the area in which Moscamed operates, are generated by the El Niño/La Niña cycle, with dry/hot years occurring with the El Niño phenomenon. In summary, an "El Niño Lead-in Year" will drive to a "medfly-storm year". With this pattern detected, Auclair et al. (2008), generated the "El Niño Forecast Plume", which basically suggests that before a year of interest that is expected to be a "medflystorm" year, the signal of El Niño will increase.

This model, generated in 2008, was executed again in 2015 (Allan Auclair, personal communication). An updated version of the model, together with the ENSO data for 2015 led to a prediction that 2016 was going to be an outbreak year. The prediction by Auclair was borne out in 2016, which was indeed a fly-storm year. The maximum number of captures in 2016 was much above the normal captures and much higher compared with 2014 and 2015 (Fig. 14).

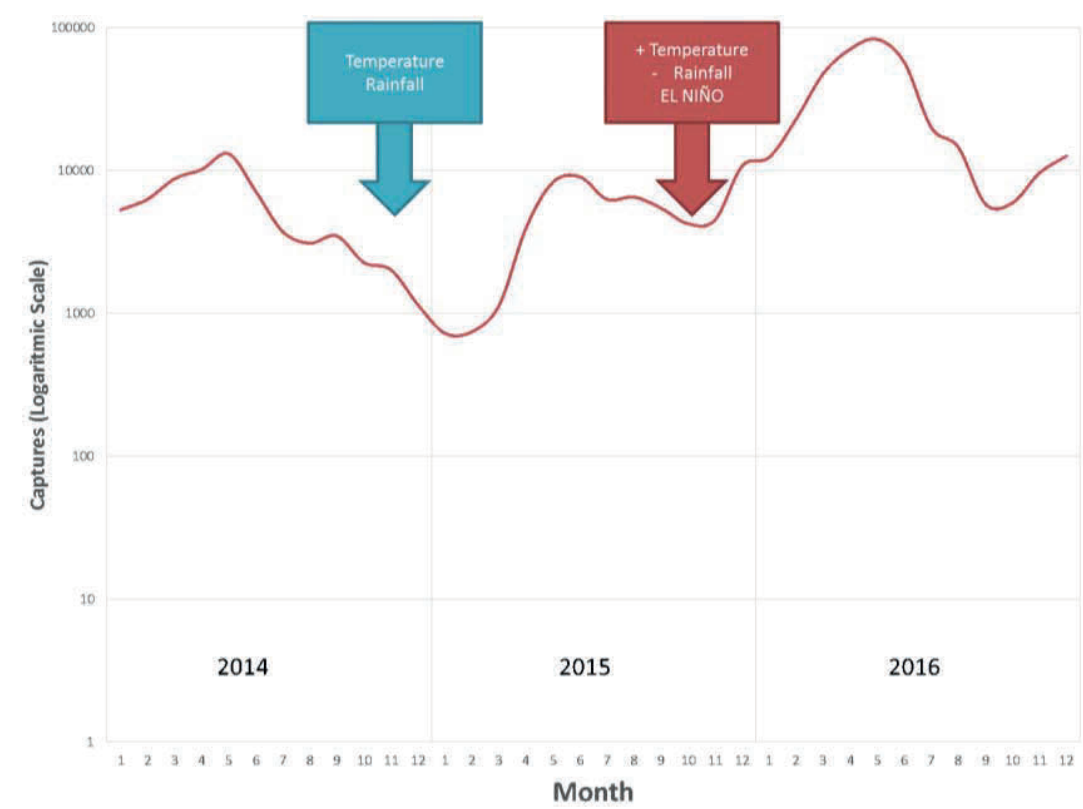

Figure 14. Number of fertile medfly captures per month from 2014 to 2016 in the region (the authors, based on the information of Moscamed).

By overlaying the medfly captures with the ENSO Anomalies from 2015 to 2017 and the Forecast Plume, it can be observed that what Auclair predicted in 2015 was correct; as shown in Fig. 15.

\section{DISTRIBUTION AND PREDICTION MODELS}

In this Section we generate medfly distribution models based on the information generated by Moscamed, and analysis of population demographics due to the ecological variables mentioned above (host, temperature and soil texture). 


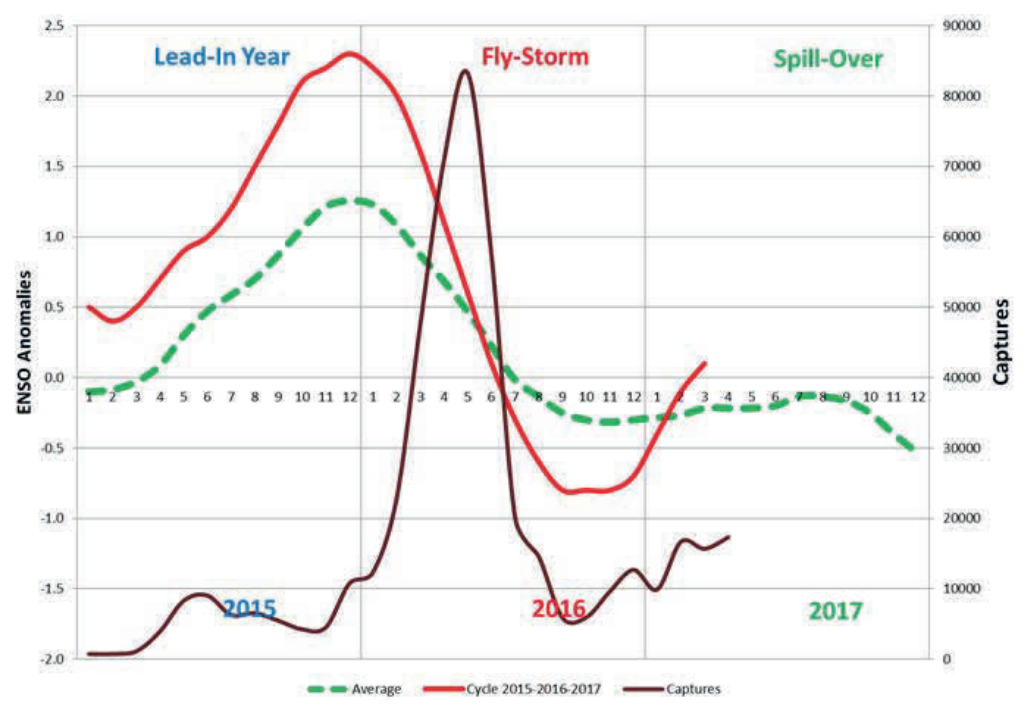

Figure 15. El Niño signal (left y-axis), outbreak years and medfly capture from 2015 to 2017 (right y-axis). The green dotted line is the "El Niño Forecast Plume" for an outbreak year generated by Auclair et al. (2008). The red solid line is the El Niño signal as reported by NOAA (2017). The brown continuous line is the total number of captures for medfly in the region from 2015 to 2017 (the authors, based on information of Moscamed, Auclair et al. 2008 and NOAA 2017).

Trapping information (a dataset of 17014 traps serviced from 2004 to 2015) was overlaid with the ecological factors in order to estimate the distribution of the medfly in areas with no traps in Guatemala, using the maximum entropy software (Maxent) (Phillips et al. 2006). Maxent is a software widely used for modelling species distribution. It uses machine learning methods to statistically estimate the relationships within species presence locations (response variable) and a set of environmental predictors (explanatory variables). The response variable selected was the maximum number of flies captures in one trap in one week. Moscamed uses Jackson (trimedlure attractant) and Phase IV (open-bottom baited with a dry foodbased synthetic attractant) traps for monitoring the wild populations.

According to Midgarden et al. (2004) there is no significant difference in the total number of wild flies captured for these two types of traps. So, both trap types were included in the analysis. This variable represents the maximum level of infestation in one site. The explanatory variables selected were:

1. Distance to coffee - as a measurement of the main host, generated using the coffee production areas from the land use map of Guatemala (GIMBOT 2014).

2. Temperature - variable related with the life cycle, generated from the INSIVUMEH weather stations in the digital database of MAGA (2001).

3. Soil texture - classified for clay to sandy, as a measurement of the effect of this condition on the larval/pupal stage, obtained from the soil maps of Guatemala (MAGA 2001). 
With the GIS, the information was prepared to be able to use it in Maxent. The results of the modelling are presented in Fig. 16. The output is the logistic probability of presence of medfly, ranging between values from 0 to 1 .

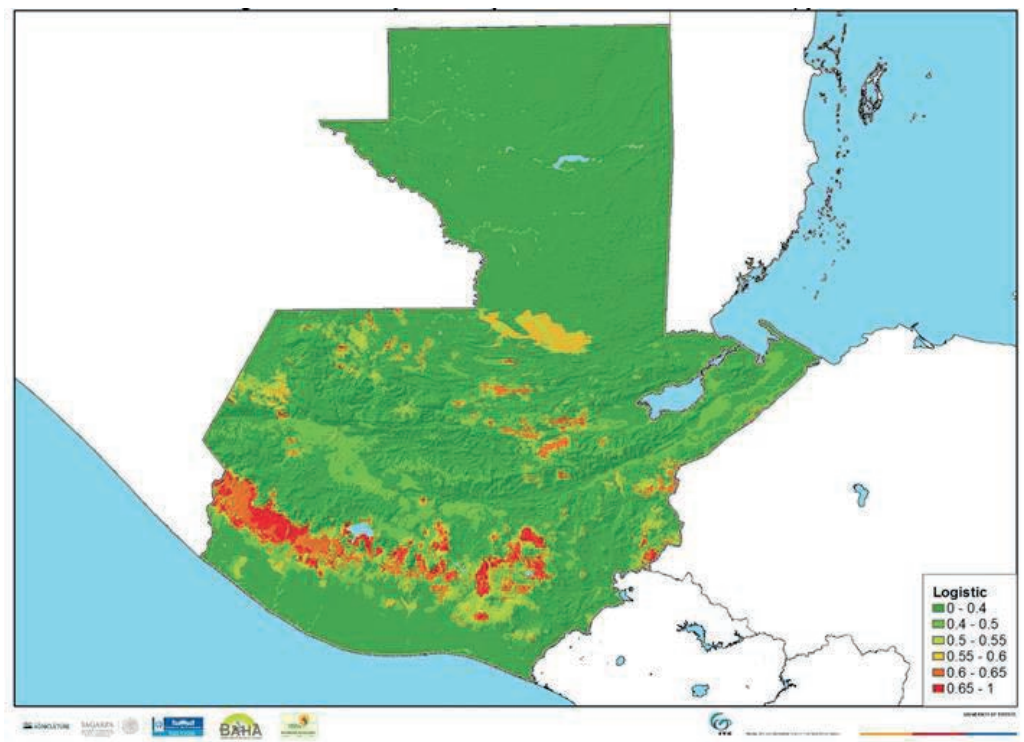

Figure 16. Logistic probability of medfly occurrence in Guatemala using the maximum entropy (Maxent) method (the authors, based on information of Moscamed).

The IPCC observations regarding temperature indicate that the total temperature increase from $1850-1899$ to $2001-2005$ is $0.76^{\circ} \mathrm{C}\left[0.57^{\circ} \mathrm{C}\right.$ to $\left.0.95^{\circ} \mathrm{C}\right]$ (IPCC 2007). Hansen et al. (2013) observed that the global surface temperature in 2012 was $+0.56^{\circ} \mathrm{C}$ $\left(1^{\circ} \mathrm{F}\right)$ warmer than the 1951-1980 base period average. Rahmstorf et al. (2012) observed that global mean temperature has been increasing due to climate change at a rate of $0.16^{\circ} \mathrm{C} /$ decade.

With these observations of consistent temperature increases and the wide range of medfly tolerances to temperatures (minimum and maximum), it is expected that fly populations will increase each year under normal conditions. To estimate the effect of increasing temperature due the climate change, the temperature in Maxent was modified by adding $1^{\circ} \mathrm{C}$. The results of that estimation are shown in Fig. 17 .

According to the modelling conducted, and the prediction of the increase of temperature, it seems that in some areas the probability of occurrence of medfly will increase at higher altitudes, mainly in the temperate areas, but in lower altitudes (subtropical areas) this probability will decrease. This prediction might be explained by the fact that medfly has lower and higher temperature thresholds. As indicated before, it is expected that the maximum potential for presence of medfly will occur in areas with yearly average temperatures of around $20^{\circ} \mathrm{C}$. 


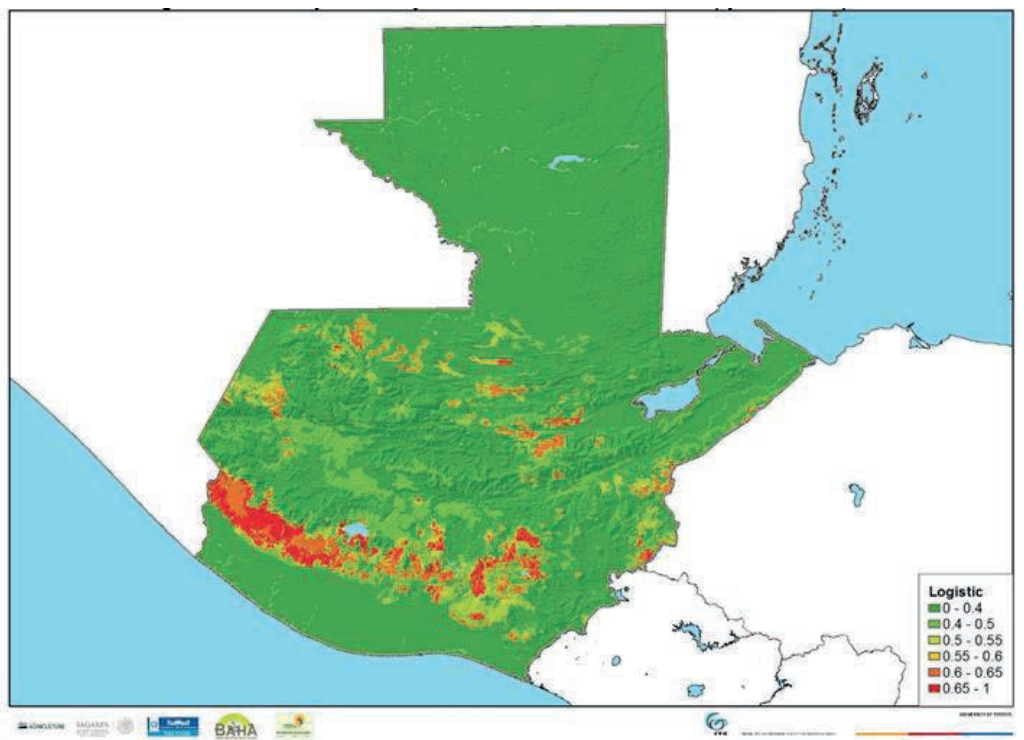

Figure 17. Logistic probability of medfly occurrence in Guatemala using the maximum entropy (Maxent) method and considering an increase in temperature of $1{ }^{\circ} \mathrm{C}$ (the authors, based on information of Moscamed).

In the subtropical areas, the temperature is higher than this temperature, in consequence the increase in temperature might decrease the probability of medfly occurrence. In contrast, in the temperate areas, the temperature is below the optimal temperature of $20^{\circ} \mathrm{C}$, and the expected increase in temperature might also increase the probability of medfly occurrence, since the temperature will be closer to the optimal. Fig. 18 shows the expanded area of south-western Guatemala, where this contrast can be appreciated.
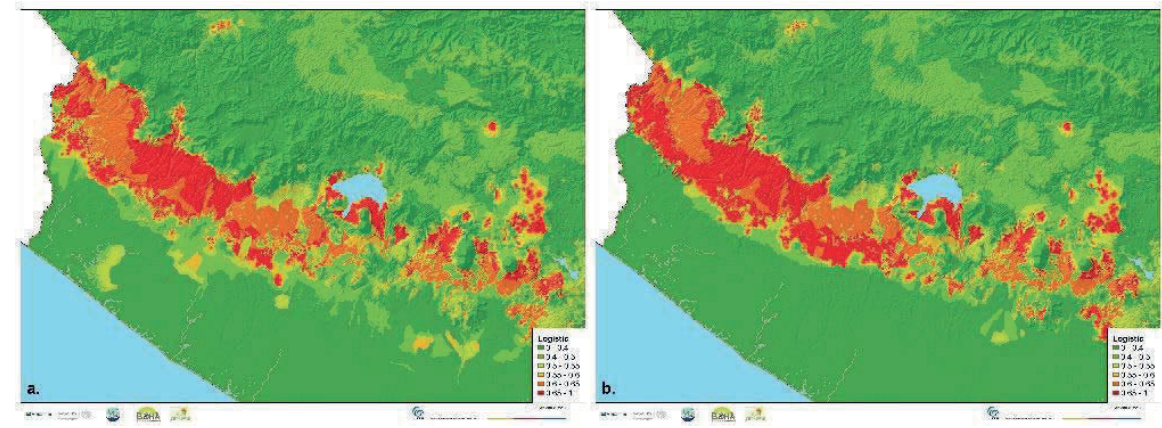

Figure 18. "Zoom-in" to the south-western area of Guatemala to see the differences between the modelling with current temperature (a.) and with an increase of temperature by $1{ }^{\circ} \mathrm{C}(\mathrm{b}$.) (the authors, based on information of Moscamed). 
Further analyses should include other levels of temperature increases and the effect of increased variance of temperature. Future analysis should also consider other explanatory variables, as well as using other modelling techniques for species distribution.

\section{CONCLUSIONS}

Climate change including temperature increase appears inevitable. Nevertheless, understanding how this will affect the population ecology of a pest will provide programme managers with key information for decisions on insect pest management that can minimize the negative effects of these changes.

Knowledge about the effects of climate, in particular temperature and other ecological factors, such as host phenology and the population trends of medfly, has allowed us to develop a predictive model that can be applied as a decision-making tool in support of effective medfly programme management. Temperature shifts from climate change have a direct impact on medfly populations. Furthermore, hot and dry El Niño years will increase the reproductive rate of the pest, resulting in overall population increase, whereas cold La Niña years will have the opposite effect, resulting in population reduction. Well-coordinated AW-IPM activities based on information analysis is crucial to avoid the increases of medfly populations. With the prediction models generated, early warnings can be provided to high-level decisionmakers and programme managers to act in an effective and timely-manner, including shifting programme strategies and assigning larger budgetary resources to the programme when expecting difficult years.

\section{ACKNOWLEDGEMENTS}

The authors would like to thank Nick C. Manoukis and Walther Enkerlin for many suggestions that significantly improved this manuscript.

\section{REFERENCES CITED}

ANACAFE (National Association of Coffee). 2008. Personal communication with Oscar García, Technician of ANACAFE, Guatemala.

ANACAFE (National Association of Coffee). 2014. ANACAFE Weather Stations System.

Auclair, A., C. Chen, W. Macheel, P. Rendón, E. Lira, D. Midgarden, R. Magery, D. Enfield, and A. Anyamba. 2008. Using climate indices to predict Medfly outbreaks in Guatemala and Mexico. Poster presented at the $7^{\text {th }}$ meeting of the Working Group on Fruit Flies of the Western Hemisphere, November 2008, Mazatlán, México.

Enkerlin, W., J. M. Gutiérrez-Ruelas, A. V. Cortes, E. C. Roldan, D. Midgarden, E. Lira, J. L. Z. López, J. Hendrichs, P. Liedo, and F. J. T. Arriaga. 2015. Area freedom in Mexico from Mediterranean fruit fly (Diptera: Tephritidae): A review of over 30 years of a successful containment program using an integrated Area-Wide SIT approach. Florida Entomologist 98: 665-681.

Enkerlin, W., A. Villaseñor, S. Flores, D. Midgarden, E. Lira, P. Rendon, J. Hurley, E. Salazar, W. Méndez, R. Castañeda, E. Cotoc, J. L. Zavala, H. Celedonio, and J. M. Gutiérrez Ruelas. 2016. Descriptive analysis of the factors affecting population fluctuation of the Mediterranean fruit fly (Ceratitis capitata, Wied.) in coffee areas located in Guatemala and its implications in IPM Strategies, pp. 46-63. In B. Sabater-Muñoz, T. Vera, R. Pereira, and W. Orankanok (eds.), Proceedings of the 9th International Symposium on Fruit Flies of Economic Importance, Bangkok, Thailand. 
Enkerlin, W. R., J. M. Gutiérrez Ruelas, R. Pantaleon, C. Soto Litera, A. Villaseñor Cortés, J. L. Zavala López, D. Orozco Dávila, P. Montoya Gerardo, L. Silva Villarreal, E. Cotoc Roldán, F. Hernández López, A. Arenas Castillo, D. Castellanos Dominguez, A. Valle Mora, P. Rendón Arana, C. Cáceres Barrios, D. Midgarden, C. Villatoro, E. Lira Prera, O. Zelaya Estradé, R. Castañeda Aldana, J. López Culajay, F. Ramírez y Ramírez, P. Liedo Fernández, G. Ortíz Moreno, J. Reyes Flores, and J. Hendrichs. 2017. The Moscamed regional programme: Review of a success story of Area-Wide Sterile Insect Technique application. Entomologia Experimentalis et Applicata 164: 188-203.

Eskafi, F., and M. Fernandez. 1999. Larval-pupal mortality of Mediterranean fruit fly (Diptera: Tephritidae) from interaction of soil, moisture, and temperature. Environmental Entomology 19: $1666-1670$

Grout, T., and K. Stoltz. 2007. Developmental rates at constant temperatures of three economically important Ceratitis spp. (Diptera: Tephritidae) from Southern Africa. Environmental Entomology 36: $1310-1317$.

GIMBOT (Grupo Interinstitucional de Monitoreo de Bosques y Uso de la Tierra). 2014. Mapa de bosques y uso de la tierra 2012 y mapa de cambios en uso de la tierra 2001 - 2010 para estimación de emisiones de gases de efecto invernadero. Documento informativo. 16 pp. Ministerio de Ambiente y Recursos Naturales. Gobierno de la República de Guatemala, Guatemala City, Guatemala.

Gutiérrez Samperio, J. 1976. La Mosca del Mediterraneo Certatitis capitata (Wiedeman) y los factores ecológicos que favorecerían su establecimiento y propagación en México. Dirección General de Sanidad Vegetal. SAGARPA. Talleres Gráficos de la Nación. México, D. F., México. pp. 223.

Hansen, J., M. Sato, and R. Ruedy. 2013. Global temperature update through 2012. Columbia University, New York, NY, USA.

Hendrichs, J., M. J. B. Vreysen, W. R. Enkerlin, and J. P. Cayol. 2021. Strategic options in the use of the Sterile Insect Technique, pp. 841-884. In V. A. Dyck, J. Hendrichs, and A. S. Robinson (eds.), Sterile Insect Technique - Principles and practice in Area-Wide Integrated Pest Management. Second Edition. CRC Press, Boca Raton, Florida, USA.

Houghton, J. T. 2015. Global warming: The complete briefing. Cambridge University Press. 5th Edition. Cambridge, UK. 454 pp.

Huisman, O., and R. de By. 2009. Principles of Geographic Information Systems: An introductory textbook. International Institute for Geo-Information Science and Earth Observation. Enschede, The Netherlands. 540 pp.

IPCC (Intergovernmental Panel on Climate Change). 2007. Summary for policymakers, pp. 1-17. In S. Solomon, D. Qin, M. Manning, Z. Chen, M. Marquis, K. B. Averyt, M. Tignor and H. L. Miller (eds.), Climate change 2007: The physical science basis. Contribution of working group I to the Fourth Assessment Report of the Intergovernmental Panel on Climate Change. Cambridge University Press, Cambridge, United Kingdom and New York, USA.

IPCC (Intergovernmental Panel on Climate Change). 2018.

Lira, E. 2010. Uso de sistemas de información geográfica, pp. 159-165. In P. Montoya, J. Toledo, and E. Hernandez (eds.), Moscas de la fruta: Fundamentos y procedimientos para su manejo. S y G Editores. México, D. F., México.

MAGA (Ministerio de Agricultura, Ganadería y Alimentación de Guatemala). 2000. First approximation to the taxonomic classification of the soils of the Republic of Guatemala, scale 1:250,000. Technical memory. Financial support of: Plan de acción forestal para Guatemala (PAFG); Instituto Nacional de Bosques (INAB). Guatemala, Guatemala.

MAGA (Ministerio de Agricultura, Ganadería y Alimentación). 2001. Base de datos espacial digital de Guatemala. Digital information generated by Banco Interamericano de Desarrollo (BID) 1147/OC-GU, Unidad de Políticas e Información Estratégica (UPIE-MAGA), Guatemala, and Centro Agronómico Tropical de Investigación y Enseñanza (CATIE), Costa Rica.

McGovern, T., E. Lira, and P. Rendón. 2008. Medfly program operational update: Targeted suppression of population centers of Ceratitis capitata Wied. through the use of GIS/GPS technology, pp. 9-10. In P. Montoya, F. Fleischer, and S. Flores (eds.), Proceedings of the $7^{\text {th }}$ meeting of the Working Group on Fruit Flies of the Western Hemisphere. Mazatlán, México.

Midgarden, D., and E. Lira. 2008. Ecological relationship of Medfly and coffee in Guatemala and Mexico, pp. 241-247. In R. Sugayama, R. Zucchi, S. Ovruski, and J. Sivinski (eds.), Fruit Flies of economic importance: From basic to applied knowledge. Proceedings of the 7 th International Symposium on Fruit Flies of Economic Importance. 10-15 September 2006. Salvador, Bahia, Brazil. 
Midgarden, D., E. Lira, and M. Silver. 2014. Spatial analysis of tephritid fruit fly traps, pp. 277-320. In T. Shelly, N. Epsky, E. Jang, J. Reyes-Flores, and R. Vargas (eds.), Trapping and the detection, control, and regulation of tephritid fruit flies: Lures, area-wide programs, and trade implications. Springer Science+Business Media, Dordrecht, The Netherlands.

Midgarden, D., O. Ovalle, N. Epsky, H. Puche, P. Kendra, P. Rendon, and R. Heath. 2004. Capture of Mediterranean fruit flies (Diptera: Tephritidae) in dry traps baited with a food-based attractant and Jackson traps baited with trimedlure during sterile male release in Guatemala. Journal of Economic Entomology 97: 2137-2143.

NOAA (U.S. National Oceanic and Atmospheric Administration). 2017. Historical El Niño / La Niña episodes (1950-present).

Pedigo, L. 1996. Entomology and pest management. Second Edition. Prentice Hall. New Jersey, USA. $679 \mathrm{pp}$.

Rahmstorf, S., G. Foster, and A. Cazenave. 2012. Comparing climate projections to observations up to 2011. Environmental Research Letters 7: 044035.

Phillips, S., R. Anderson, and R. Schapire. 2006. Maximum entropy modeling of species geographic distribution. Ecological Modelling 190: 231-259.

Rendón, P. 2008. Induction of sterility in the field. Proceedings of the $7^{\text {th }}$ meeting of the Working Group on Fruit Flies of the Western Hemisphere, November 2-7, 2008, Mazatlán, México.

Ricalde, M. P., D. E. Nava, A. E. Loeck, and M. G. Donatti. 2012. Temperature-dependent development and survival of Brazilian populations of the Mediterranean fruit fly, Ceratitis capitata, from tropical, subtropical and temperate regions. Journal of Insect Science 12(1): 33.

Simmons, C., J. Tarano, and J. Pinto. 1959. Clasificación de reconocimiento de los suelos de la República de Guatemala. Instituto Agropecuario Nacional. Servicio Cooperativo Inter-Americano de Agricultura, Ministerio de Agricultura. Guatemala City, Guatemala. 1000 pp.

USDA (United States Department of Agriculture). 2003. Mediterranean fruit fly action plan. Animal and Plant Health Inspection Service (APHIS). Plant Protection and Quarantine.

Wang, C., C. Deser, J.-Y. Yu, P. DiNezio, and A. Clement. 2017. El Niño and Southern Oscillation (ENSO): A review, pp. 85-106. In P. W. Glynn, D. Manzello, and I. Enochs (eds.), Coral reefs of the eastern tropical Pacific. Coral reefs of the world 8. Springer Science+Business Media, Dordrecht, The Netherlands.

WMO (World Meteorological Organization). 1992. International meteorological vocabulary. WMONo.182. Secretariat of the World Meteorological Organization, Geneva, Switzerland. 